\title{
Posición socioeconómica, discriminación y color de piel en México
}

\author{
Luis Ortiz Hernández,* César Iván Ayala Guzmán, ${ }^{* *}$ \\ Diana Pérez-Salgado***
}

Perfiles Latinoamericanos, 26(51)

2018 | pp. $215-239$

DOI: $10.18504 / \mathrm{pl} 2651-009-2018$

\begin{abstract}
Resumen
Este artículo documenta las diferencias en posición socioeconómica, experiencias de discriminación y autopercepción de acuerdo al color de piel en adultos mexicanos, considerando que esta última es un reflejo del fenotipo simbólicamente vinculado al ancestro geográfico (i. e., indígena, africano o europeo). La premisa es que en la sociedad mexicana prevalece una asociación de lo europeo con rasgos positivos (i. e., "privilegio blanco") y lo africano e indígena con aspectos negativos, lo cual deriva en prácticas racistas. Con ese fin se analizó la Encuesta Nacional sobre Discriminación en México. Los resultados indican que, con excepciones, los blancos acceden más a la educación, se ubican en mejores ocupaciones, tienen salarios mayores, con menos frecuencia han experimentado discriminación y les gusta más su piel. Conforme la piel es más oscura, la situación es opuesta.
\end{abstract}

\begin{abstract}
This article documents the differences in socioeconomic position, discrimination experiences and self-perception according to skin color among Mexican adults, considering that the last is a proxy of the phenotype symbolically associated with geographic ancestry (i. e., African, indigenous, or European). The analysis is based on the premise that in Mexican society prevailing an ideology that associates European characteristics with positive traits (i. e., "white privilege"), while African and indigenous characteristics are negatively valued (which results in racist practices). To achieve the objective the National Survey on Discrimination in Mexico was analyzed. The results indicate that, with exceptions, whites have more access to education, better jobs, and higher wages; with less frequency experience discrimination and like their skin. As the skin is darker the opposite trend is verified.
\end{abstract}

Palabras clave: racismo, privilegio blanco, discriminación, indígenas, morenos, desigualdad, México, color de piel.

Keywords: racism, white privilege, discrimination, indigenous, brown people, inequality, Mexico, skin color.

* Doctor en Ciencias en Salud Colectiva por la Universidad Autónoma Metropolitana, Unidad Xochimilco. Profesor investigador, Departamento de Atención a la Salud, Universidad Autónoma Metropolitana, Unidad Xochimilco | lortiz@correo.xoc.uam.mx

** Licenciado en Nutrición Humana por la Universidad Autónoma Metropolitana, Unidad Xochimilco. Asistente de investigación, Departamento de Atención a la Salud, Universidad Autónoma Metropolitana, Unidad Xochimilco | nutrivan@hotmail.es

*** Licenciada en Nutrición por la Universidad Autónoma Metropolitana, Unidad Xochimilco. Profesora, Departamento de Atención a la Salud, Universidad Autónoma Metropolitana, Unidad Xochimilco | dianaps2006@gmail.com 


\section{Introducción}

- 1 a premisa fundamental de este trabajo es que en México el racismo se expresa en el no respeto de los derechos humanos de tres grupos de personas: indígenas, afrodescendientes y morenas. La intención es documentar las disparidades socioeconómicas y experiencias de discriminación entre los grupos, enfatizando en las desventajas de los morenos respecto de los blancos. La inequidades a las que se enfrentan los indígenas son reconocidas tanto por la mayoría de la población, como por académicos y los gobiernos (Saldívar, 2012). En contraste, un aspecto poco analizado en México en particular y en América Latina en general, es que dentro de la población urbana existe trato diferenciado en función del color de la piel. Las desventajas de los afrodescendientes o de los morenos han sido más difíciles de evidenciar y estudiar ya que se expresan en formas sutiles o veladas (Moreno, 2008; Ortiz, Compean, Verde \& Flores, 2011).

Recientemente se han comenzado a indagar las experiencias de racismo a las que se enfrentan los morenos (Moreno, 2008, 2012; Ortiz, Hernández \& Compean, 2011). El conocimiento generado en la investigación antropológica (por medio de entrevistas con muestras reducidas) es valioso, pues permite generar hipótesis que deben ser verificadas en muestras representativas de la población mexicana. Por otra parte, análisis de la encuesta Latin American Barometer han mostrado la estrecha relación que tienen el color de piel con la posición socioeconómica (Aguilar, 2013; Flores \& Telles, 2012; Villarreal, 2010). Sin embargo, con excepción de un estudio hecho con una muestra pequeña por conveniencia (Ortiz, Hernández \& Compean, 2011), hasta ahora ningún otro ha analizado la preferencia por el color de piel, ni las experiencias de discriminación en áreas relevantes como los servicios de salud o educativos, o el trabajo.

La persistencia del racismo en México hace necesario el desarrollo de estudios encaminados a documentar su papel en la generación de desigualdades, por ello en la segunda sección del artículo se presenta una propuesta conceptual con ese propósito. En la tercera, se reseña un panorama de aspectos clave de la historia de México para responder sobre cuál es el origen de las inequidades racistas en este país y como han sido reproducidas. Para corroborar las hipótesis derivadas del modelo conceptual se analizó una encuesta representativa de la población adulta mexicana, un abordaje metodológico que se describe en la cuarta sección. Posteriormente, los resultados relativos a las disparidades racistas en posición socioeconómica, discriminación y autopercepción se comentan a la luz de la teoría propuesta. La sección final ofrece unas conclusiones relacionadas con el estudio del racismo y las implicaciones de nuestros resultados para la construcción de una sociedad incluyente. 


\section{Aproximación teórica}

El término raza ha sido criticado porque hace referencia a grupos genéticamente homogéneos a su interior y que pueden ser distinguidos entre sí. Sin embargo, tales grupos no existen, situación especialmente cierta para habitantes de Latinoamérica. Además, en la vida cotidiana la sociedad mexicana no utiliza la noción de raza como en otras (e. g., Estados Unidos de América, Canadá o Europa). Por ello, aquí se ha adoptado el término ancestro geográfico (ancestry) para denotar el continente de origen de los antepasados de las personas. En nuestro contexto de estudio, tres son los ancestros relevantes: americano (o indígena), europeo y africano.

En México, el color de piel es un marcador sociocultural del ancestro geográfico. Para simplificar el lenguaje, a lo largo del texto se utilizan los términos "morenos", "blancos" y "afrodescendientes" para referirse a las personas que se perciben o son percibidos con piel morena, blanca o negra, y que frecuentemente se asume que son descendientes de indígenas, europeos o africanos, respectivamente. Cabe aclarar que es una sobresimplificación pensar que el ancestro geográfico se corresponde con el color de piel. Es decir, es inadecuado considerar que, por ejemplo, todos los morenos son descendientes de indígenas. Por lo mismo, en ocasiones es difícil distinguir entre personas indígenas aquellas con ancestro indígena de las morenas. Al mismo tiempo, conviene retomar el trabajo de Wade (2010), según el cual las razas son construcciones socioculturales elaboradas con base en la variabilidad fenotípica. Esta concepción es cercana al concepto de racialización (Barot $\&$ Bird, 2001), la cual ocurre cuando las relaciones sociales son estructuradas por los significados asociados a las características fenotípicas de los humanos. Este proceso de significación deriva en la definición y construcción de colectividades humanas. La mayoría de las personas han creado estereotipos en los que se equipara el fenotipo (rasgos de la cara o color de piel) con el ancestro geográfico y con esto se cree que las diferencias son más o menos innatas. Estas variaciones fenotípicas son utilizadas como marcadores para crear categorías sociales mismas que a su vez son utilizadas para incluir (a los que se percibe como parte del endogrupo o in-group) o excluir (a los del exogrupo, u out-group) (Allport, 1955). El carácter de construcción sociocultural del color de piel se establece más claramente cuando se considera que su evaluación no es una cuestión "objetiva", sino que depende del contexto y de quién la percibe. Es decir, una misma pigmentación de la piel puede recibir diferentes evaluaciones dependiendo del entorno (Martínez et al., 2014).

En México, etnicidad remite a la conformación de grupos lingüísticos y se distingue entre quienes utilizan o no un idioma indígena (Martínez et al., 2014; 
Saldívar, 2012). Un problema de esta definición es que los afromexicanos quedan excluidos, ya que por lo regular hablan español. Además, las estimaciones de la población indígena varían sustancialmente si se utiliza el criterio lingüístico u otros como la autoidentificación o los antecedentes familiares (Martínez et al., 2014). Al respecto, Wade (2010) considera que la etnicidad se refiere a las diferencias culturales que son construidas en torno al espacio geográfico de origen. Ellas incluyen el idioma, pero no se agotan con él. Claro está que las diferencias objetivas del lugar de origen de las personas y sus antepasados no son tan relevantes como las percepciones de las personas al respecto.

Es problemático estudiar a los morenos, pues no son un grupo social con origen y/o identidad comunes. Por esto es útil proponer que el color de piel sirve de marcador para crear categorías socioculturales de modo que las personas reciben cierto trato y viven experiencias similares en función de esa característica; esto a pesar de no identificarse como parte de un grupo (Aguilar, 2013). Así, en Latinoamérica el color de piel es una dimensión de la racialización que no puede ser subsumido bajo las nociones tradicionales de raza y etnicidad (Telles \& Flores, 2014).

El racismo es un conglomerado de creencias, actitudes, arreglos institucionales o actos que denigran y excluyen a individuos o grupos debido a sus características fenotípicas vinculadas simbólicamente a su ancestro geográfico o a su afiliación a un grupo étnico (Clark et al., 1999). Se han identificado dos manifestaciones del racismo (Gall, 2004): a) El de la desigualdad, en el cual el grupo dominante considera que el o los grupos subordinados son inferiores, por lo cual deben mantenerse subordinados. Esta situación se justifica con discursos biologizantes de las diferencias culturales. $b$ ) El racismo de la diferencia, en el cual se exaltan las diferencias culturales de los grupos para justificar la exclusión de los que no son similares. La primera manifestación fue la más común hasta la emergencia de movimientos sociales que denunciaron el racismo. Mientras que la segunda es la forma más prevalente en la actualidad, dado que difícilmente se puede sostener el argumento de la inferioridad biológica de ciertos grupos (Gall, 2004; Quillian, 2006). Las nuevas formas de racismo son más sutiles e incluyen creencias sobre la supuesta responsabilidad de los propios grupos dominados respecto de sus peores condiciones de vida, o bien su incapacidad para adherirse a los valores culturales del grupo dominante (Quillian, 2006).

El racismo permea diferentes niveles y ámbitos de la vida social: políticas, reglamentaciones, arreglos institucionales y el trato interpersonal. Y uno de sus pilares son los estereotipos en los que se considera que los grupos son homogéneos y se les atribuyen ciertas características (Castellanos, 2003). De lo anterior deriva el término prejuicio, definido como una "actitud hostil o prevenida hacia una persona que pertenece a un grupo, simplemente porque pertenece a 
ese grupo, suponiéndose por lo tanto que posee las cualidades objetables atribuidas al grupo" (Allport, 1955: p. 22). Sin embargo, los prejuicios son una distorsión de la realidad, pues se generaliza un atributo a un grupo de personas, lo cual en realidad nunca ocurre ya que no todas las personas de un grupo lo tendrán (e. g., hay blancos de baja posición socioeconómica). El concepto de racismo dirige la mirada hacia la identificación de las desventajas de indígenas, afrodescendientes y morenos. Sin embargo, con la noción de racismo no se explicita entre quiénes se presentan las desventajas. Como se verá en la siguiente sección, en México la desvalorización de lo indígena y africano se hizo y se hace en relación con la sobrevalorización de lo europeo.

El privilegio blanco refiere a las ganancias, ventajas o beneficios simbólicos y/o materiales que obtienen las personas de piel clara en función de los estereotipos positivos asociados con los rasgos europeos (Harris, 1993). Históricamente, el ser europeo (i. e., blanco) incrementó la posibilidad de controlar aspectos críticos de la vida, al tiempo que garantizó no ser objeto de dominación por parte de otras personas o grupos. El privilegio blanco - como otras ideologías - existe independientemente del deseo de las personas, pues se construyó históricamente con la hegemonía de las culturas europeas durante siglos de colonialismo e imperialismo. Además de su temor a las diferencias étnicas y/o fenotípicas, los que se benefician del privilegio blanco han desarrollado la expectativa de que son sujetos de derechos (entitlement), lo que incluye no ser maltratados, explotados o tratados de manera injusta, ni lidiar injustamente con responsabilidades o tareas que exceden a sus capacidades. Es decir, mientras que se espera que los blancos reciban o exijan el trato y los beneficios de ser humanos y/o ciudadanos, a las personas que no son blancas se les niega o cuestiona su condición de humanos o ciudadanos y así son excluidos de los beneficios que implica el privilegio blanco. ${ }^{1}$

El privilegio blanco puede ser conceptualizado como una fuente de capital simbólico (Bourdieu, 1996), puesto que se trata de un estatus o valor socialmente reconocido a un grupo por un juicio colectivo construido según las categorías fundamentales de la visión compartida del mundo. Los eurodescendientes cuentan con dicho capital simbólico; mientras que los indígenas y afrodescendientes no disponen de él. Desde la colonia, los "mestizos" y "mulatos", al contar parcialmente con ancestro europeo han podido tomar parte del provecho del privilegio blanco, de modo que han ocupado posiciones intermedias en la jerarquía ocupacional y de estatus (McCaa, Schwartz \& Grubessich, 1979). En

1 Hay preocupación porque una niña blanca pida limosna, pero se ignora sistemáticamente que miles de nińos morenos y/o indígenas pasan cotidianamente por esa situación (Proceso, 30 de octubre de 2012; La Jornada, 7 de agosto de 2014). 
otras palabras, la calidad de ciudadano o humano - y por tanto el trato que se espera recibir y se recibe- se logra en función de la cercanía o lejanía con los rasgos europeos (Harris, 1993). Hay que reiterar que el privilegio blanco no deriva de un hecho biológico (i. e., la ascendencia europea), sino que se trata de un constructo sociocultural en tanto que la supuesta superioridad de un fenotipo depende del reconocimiento de las personas. Con la noción de capital simbólico se reconoce que las formas de dominación siempre tienen dos facetas: una material de la que deriva la simbólica, al tiempo que la segunda justifica a la primera. Es decir, ser blanco ha sido acompañado de privilegios materiales (más educación, mejor ocupación y mejores condiciones de vida), por lo cual simbólicamente se asoció el ser blanco con esa condición privilegiada, y por esto actualmente funciona como un símbolo que la mayoría de las personas acepta o reconoce que alguien que lo tiene merece ser tratado como superior. El "valor" del privilegio blanco como capital simbólico se ha mantenido mediante dispositivos discursivos ${ }^{2}$ con los que se le hace pasar como un bien puro, exclusivo y escaso (Harris, 1993).

Las diferentes formas del capital simbólico son posibles debido al habitus (Bourdieu, 1996), una estructura cognitiva estructurada y estructurante: es estructurada porque es producto de la socialización de los valores dominantes y es estructurante porque define las maneras en que los individuos perciben, piensan y actúan en función de esos valores. Debido al habitus, los valores socialmente construidos se perciben como naturales, universales, inmutables e inevitables entre los individuos que los portan. El contenido del habitus difiere entre el grupo dominante (los blancos) y el de los dominados (indígenas, afrodescendientes y morenos). Los oprimidos reconocen y aceptan los instrumentos de conocimiento que los oprimen, adoptando así la lógica del prejuicio desfavorable y contribuyendo a su propia opresión. Cuando los oprimidos incorporan y aceptan los valores dominantes viven experiencias subjetivas negativas (vergüenza, modestia, timidez, pudor o angustia). Para el grupo dominante, el habitus deriva en las expectativas de trato preferencial y en la posibilidad de desarrollar una identidad positiva, pues considera que cuenta con el capital simbólico del que carecen los dominados. La noción de habitus es congruente con la teoría de justificación del sistema (Jost, Banaji \& Nosek, 2004), la cual plantea que la mayoría de las personas están motivadas a justificar el orden social prevaleciente. En el caso de los grupos dominados, ello derivaría de que han internalizado su inferioridad, lo cual con frecuencia ocurre en un nivel no consciente.

2 Ejemplos de la cultura popular: "gente bien", "viene de buena familia", "es algo con lo que se nace" o "es de buena cuna". 


\section{Esbozo de la historia del racismo en México}

Esta sección evidencia cómo el racismo ha persistido a lo largo de la historia de México, lo cual servirá de contexto para comprender la concepción y los resultados del estudio central del artículo. El racismo en México, como en la mayor parte de América Latina, se origina en las colonias que España y otros países europeos fundaron en la región. Durante esa etapa, para justificar la explotación económica de indígenas y afrodescendientes, se desarrolló un sistema de categorías jerarquizadas o sistema de castas, ubicando a la población española en la cúspide de la estratificación y a las naciones indígenas y afrodescendientes (traídos a América como esclavos) en la base. Para ello se argumentó que estos últimos eran biológica y culturalmente inferiores (Knight, 1990; Morner, 1966). Incluso entre los afrodescendientes e indígenas aparecieron jerarquías, pues los primeros por ser esclavos tenían más restricciones legales, lo que implicó la pérdida de su condición humana para ser reducidos a objetos (Morner, 1966). Los indígenas, por otra parte, se destinaron a ser sirvientes y se les permitió formas limitadas de autogobierno (Morner, 1966). A partir de entonces, los rasgos físicos de las personas, en especial el color de la piel, fueron utilizados como marcadores socioculturales para dar y aceptar diferentes tratos.

Durante la colonia diferentes procesos llevaron al establecimiento y reproducción de las jerarquías racistas vinculadas con el ancestro geográfico (McCaa et al., 1979; Morner, 1962, 1966): con el sistema de castas surgió la estratificación racista, pues fue formulado para definir las "razas" y proscribir la mezcla entre estas. Los pueblos indígenas fueron despojados de sus tierras y se les obligó a pagar tributos a los españoles; indígenas y afrodescendientes fueron sometidos a trabajo forzado; se decretaron leyes en las que se prohibía el acceso a indígenas y afrodescendientes a la educación universitaria y a oficios de mayor prestigio; dentro de las áreas urbanas se segregó espacialmente a los indígenas separándolos de europeos y africanos, y aunque el sistema de castas no fue del todo cerrado, el nivel de endogamia era alto, lo que garantizó la reproducción de las desigualdades.

En esa misma época se consolidó la creencia de la superioridad de la ascendencia europea (Morner, 1962), lo cual legitimó las ventajas materiales de los eurodescendientes. La idea de pureza de sangre hacía, y hace, referencia al deseo de los españoles por evitar su mezcla con indígenas o afrodescendientes. $\mathrm{Al}$ mantener su pureza mantenían los privilegios que el sistema les garantizaba. Aunque toleradas, las mezclas entre castas, o mestizaje, resultaban indeseables, debido a que implicaba que la sangre española perdía pureza y se degradaba así su estatus. Para la contraparte indígena o afrodescendiente esto mismo significó mejorar su posición social. Los límites entre castas siempre fueron una 
convención ya que, por ejemplo, los mestizos o mulatos podían comprar títulos para ser considerados "blancos".

Con la independencia las castas desaparecieron como entidades legales, pero en los hechos persistieron las desigualdades racistas (Morner, 1966). Los gobiernos liberales que siguieron a la independencia promovieron la eliminación de la propiedad comunal de la tierra, lo cual debilitó la ya limitada autonomía de las naciones indígenas. Estos no siempre podían participar en la elección de autoridades dado que hablar español era un requisito. Después de la independencia las élites españolas y criollas fueron desplazadas en el campo político; sin embargo, mantuvieron su poder económico controlando áreas clave de la economía, con lo cual lograron influir en los gobiernos (Lida, 1994).

Con el Porfiriato se implementaron políticas que promovían la inmigración de europeos a México, considerando que tenían el "talento" para contribuir al "proyecto modernizador" (Lida, 1985, 1994). Por eso a migrantes españoles (y también a norteamericanos, ingleses y franceses) se les concedieron tierras (sobre todo en el norte del país) y se les exentó de impuestos. Los migrantes aprovecharon sus vínculos con parientes o amigos para establecerse en las zonas urbanas como propietarios o trabajadores especializados en los sectores de la manufactura, el comercio, las finanzas y la agricultura de exportación. Como en la colonia, después de la independencia la "endogamia" fue una práctica común entre los españoles y sus descendientes.

En el México posrevolucionario, la construcción de la nación se basó en las narrativas del mestizaje: la fusión de las culturas española e indígena. Aunque este discurso parece inclusivo, en realidad implica la desvalorización de las raíces indígenas, pues la visión dominante era que el componente español podría eliminar los "vicios" de las primeras (Moreno, 2012; Saldívar, 2012). Paradójicamente, la política indigenista del gobierno posrevolucionario se construyó negando la existencia de "razas", pero planteaba a la vez que existían diferencias radicales entre indígenas y mestizos, por lo cual los primeros tenían que ser integrados a la cultural nacional por medio de programas educativos (Knight, 1990). En las narrativas del mestizaje la contribución de los afrodescendientes fue ignorada o invisibilizada (Hooker, 2005). Paralelamente, la mayoría de los migrantes que arribaron por la guerra civil española se insertaron —amparados por el apoyo gubernamental — con éxito al mercado laboral ocupando puestos privilegiados como académicos, profesionistas o técnicos especializados, lo cual obedeció a su alta escolaridad (Lida, 1994).

La estratificación racista basada en el fenotipo simbólicamente asociado al ancestro geográfico sigue vigente en México. Esta construcción y reproducción de la estratificación a partir del color de piel se fundamenta en dicotomías vinculadas al binomio blanco-moreno: belleza-fealdad, inteligencia-torpeza, superior-inferior, 
entre otros (Castellanos, 2005). Es común equiparar lo indígena, y a los rasgos físicos asociados, con cualidades negativas; en tanto que los rasgos europeos se asocian a aspectos positivos (Stephens, 1989). ${ }^{3}$ Se ensalza el pasado indígena considerándolo signo de identidad cultural, pero se excluye y degrada a los indígenas contemporáneos (Castellanos, 2003). ${ }^{4}$ Este discurso racista es paternalista ya que implica que la población indígena necesita ser "educada" para superar la pobreza e integrarse a la sociedad ya que su cultura es incompatible con el modelo de desarrollo dominante. Un hecho reconocido es que los morenos en contextos urbanos experimentan diferentes formas de discriminación (Moreno, 2012; Ortiz, Hernández \& Flores, 2011). Es entendible entonces por qué las personas tratan de ocultar sus orígenes indígenas (Castellanos, 2007), o evitan ciertos lugares que no son a los que sus similares acuden (Moreno, 2012).

Entre los blancos hay conciencia de sus privilegios, de modo que utilizan signos de distinción como la escolaridad o la historia familiar (el origen de sus apellidos) para mantenerse física y/o simbólicamente separados del resto de la población. ${ }^{5}$ Así se ha documentado que las élites blancas de Cancún y Chiapas se mantienen segregadas del resto de la sociedad (Castellanos, 2003). Además, a la jerarquía entre lo español y lo indígena se ha sumado la distinción entre lo mexicano versus lo norteamericano, con lo cual se ratifica la asimetría entre indígena y eurodescendiente (Castellanos, 2003).

En todas las épocas los pueblos indígenas han luchado para revertir su situación de exclusión y explotación (Castellanos, 2003, 2007; Saldívar, 2012). Sin embargo, las desventajas materiales y simbólicas históricamente construidas han hecho difícil sobreponerse a su opresión.

\section{Abordaje metodológico}

Considerando el modelo conceptual delineado arriba, se plantean las siguientes hipótesis de investigación: a) Las desigualdades racistas se expresan mediante inequidades socioeconómicas pues según el color de piel sea más oscuro y/o el ancestro europeo (real o percibido) esté ausente habrá más probabilidad de encontrarse en baja posición socioeconómica. b) Desigualdades socioeconómicas

3 Ejemplos del uso peyorativo de lo indígena: "pareces indio", "pinche prieto" o "ni las Marías". Ejemplos de lo blanco como positivo: "eso es invento de hombre blanco" o "que le damos güerita". La frase "mejorar la raza" implica ambas cosas.

4 Los casos de violencia obstétrica denunciados recientemente muestran cómo los indígenas no son considerados sujetos de derechos (Excelsior, 4 de octubre de 2013).

5 El racismo y el privilegio blanco contemporáneos son descritos en las novelas de Guadalupe Loaeza y en los cartones de Cindy La Regia del caricaturista Ricardo Cucamonga. 
y racistas se manifiestan de modo distinto en las experiencias de discriminación y las percepciones negativas que las personas tienen de sí mismas. Por tal causa se espera una relación positiva entre estas últimas y tener piel morena o hablar una lengua indígena. Asimismo, se pretende verificar si hay un gradiente racista, el cual ocurre cuando el ubicarse en baja posición económica, sufrir experiencias de discriminación y tener peor percepción de sí mismo son más probables conforme el color de piel es más oscuro.

Para verificar estas hipótesis, se analizó la base de datos de la Encuesta Nacional sobre Discriminación en México (Enadis) (Consejo Nacional para Prevenir la Discriminación, 2010). ${ }^{6}$ De 13138 adultos se obtuvo información sociodemográfica y del color de piel; y una submuestra de 6552 participantes contestó la sección sobre discriminación. Los análisis se realizaron con los datos de participantes que presentaron información en todas las variables exceptuando el ingreso y ocupación, por lo cual las muestras finales fueron de 12129 y 6022 registros, respectivamente. Los registros con datos faltantes del ingreso se mantuvieron (10 147 de los 12 129), dado que una proporción de hogares no dieron información acerca de dicha variable.

La clasificación por color de piel se llevó a cabo de dos maneras: a) Se mostró a los participantes nueve fotografías de personas de diferentes tonos de color de piel y fisonomías, luego se les preguntó cuál era el que se parecía más a su tono de piel. Se crearon tres grupos: blanco $(\mathrm{n}=2,762)$, moreno claro $(\mathrm{MC})$ $(\mathrm{n}=6,209)$ y moreno oscuro (MO) $(\mathrm{n}=3,158)$. b) Los entrevistadores utilizaron una paleta de catorce colores para clasificar el color de la piel de la frente del participante. Se formaron tres grupos: blanco $(n=2,009), M C(n=4,865)$, $\mathrm{MO}(\mathrm{n}=5,255)$. Se preguntó a las personas si hablaban alguna lengua indígena (HLI) y se creó una variable para identificar a las personas que contestaron afirmativamente a esta pregunta $(\mathrm{n}=431)$.

Se indagó el último nivel educativo (de primaria a posgrado) y los años del último nivel que cursó el participante. A partir de estas dos variables se estimó el total de años de escolaridad. De igual modo se indagó el ingreso familiar y la ocupación del participante. Para analizar la ocupación se eliminaron las personas económicamente inactivas (discapacitados, ama de casas, estudiantes y pensionados). La población económicamente activa $(\mathrm{n}=5,829)$ se clasificó en profesionistas y patrones, técnicos y educación, trabajadores formales (afiliados a la seguridad social) y trabajadores informales. Se construyó además un índice de posición socioeconómica basado en la disponibilidad de 23 bienes y servicios

6 La Enadis tiene representatividad nacional y se realizó entre octubre y noviembre de 2010. Aunque en esa encuesta se obtuvo información de individuos de dos años en adelante, aquí solo se consideraron a los de ocho y más. 
en el hogar. Mediante análisis factorial (tabla A1 del apéndice) de los bienes del hogar se identificó un solo factor que incluía 13 bienes. El índice de posición socioeconómica (PSE) fue la suma de los 13 bienes y tuvo un alfa de Cronbach de 0.83 , lo cual muestra que tiene validez interna adecuada.

El tamaño de la localidad se recodificó en rural ( $\leq 14,999$ habitantes), mixto $(15,000$ a 99,999$)$ y urbano $(\geq 100,000)$. Los estados fueron agrupados en cuatro regiones geográficas.

Se indagó si los entrevistados pensaban que en México se trata a las personas de forma distinta según el tono de piel de las personas y si alguna vez habían sentido que sus derechos no habían sido respetados por su apariencia física, color de piel, costumbres, acento al hablar o no tener dinero. También se preguntó sobre la satisfacción de los participantes con el color de su piel, para lo cual utilizaron una escala de 0 (nada) a 10 (mucho). Se preguntó si los participantes habían experimentado 18 formas de discriminación: 1) Lo trataron mal en su trabajo, 2) Le pagan menos que a otras personas por hacer el mismo trabajo, 3) Lo despiden sin justificación de su trabajo, 4) No lo quisieron atender en una clínica u hospital, 5) Solicitó los beneficios de un programa social y no se los otorgaron, 6) Ha querido inscribirse Usted (o sus hijos) en una escuela y no lo aceptaron, 7) Lo han corrido a usted (o a sus hijos) de la escuela, 8) Ha tenido algún problema de violencia familiar, 9) Ha querido entrar a un lugar público (tienda, bar, restaurante, centro nocturno, antro) y no lo dejaron, 10) Ha sido atacado o amenazado con violencia en la calle, 11) Le han dejado de hablar, hecho el vacío o aplicado la "ley del hielo", 12) Lo humillan o desprecian en público ante sus colegas o ante otras personas, 13) Tuvo un problema de violencia en la escuela, 14) Tuvo un problema de violencia en el trabajo, 15) Hacen burla de usted o bromas intentando ridiculizar su forma de hablar, de andar, etc., 16) Inventan y difunden rumores y calumnias acerca de usted, 17) Le han impedido participar en actividades grupales recreativas, deportivas o culturales, y 18) Otros, especifique cuál. En el análisis factorial de estas variables no emergió ningún elemento conceptualmente relevante, por lo cual cada pregunta se examinó por separado.

\section{Resultados y discusión}

El 22.8\% de los participantes se consideraron blancos, $51.2 \%$ se percibían como MC y 26.0\% como MO. ${ }^{7}$ Considerando la evaluación de los entrevistadores,

7 Para las estimaciones se utilizaron los comandos de encuestas complejas (svy) del programa STATA versión 3, con ello se consideró el diseńo complejo de la encuesta (probabilística, estratificada, por etapas y conglomerados). Se utilizaron los ponderadores adecuados según los estimadores obtenidos.

L. Ortiz Hernández, C. I. Ayala Guzmán, D. Pérez-Salgado | Posición socioeconómica, discriminación y color de piel en México | Perfiles Latinoamericanos, 26(51) | Flacso México | pp. 215-239| DoI: 10.18504/pl2651-009-2018 
$16.6 \%$ fueron clasificados como blancos, $40.1 \%$ como MC, $43.3 \%$ como MO. La proporción de personas que HLI fue de 3.5\%. Entre los MO fueron más bajas las proporciones de mujeres que entre $\mathrm{MC}$ y blancos.

Más blancos residían en el norte del país y en localidades urbanas (tabla 1); mientras que la frecuencia de quienes HLI y eran MO fueron mayores en los estados del sur y en las localidades rurales. Las diferencias entre regiones geográficas y el tipo de localidad se relacionan con la conformación de la sociedad mexicana: las ciudades fueron espacios creados por y para personas descendientes de europeos; además de que hubo políticas que fomentaron la colonización de la región norte del país por parte de europeos. Considerando estas diferencias, los análisis subsecuentes fueron ajustados por características demográficas y de la localidad.

\section{Disparidades en posición socioeconómica}

Durante el análisis fue clara la correlación de la escolaridad, el ingreso y la PSE por bienes con el color de piel: los blancos reportaron mayor escolaridad, seguidos por los $\mathrm{MC}$; mientras que en el otro extremo se encontraron los MO (tabla A2 del apéndice y tabla 2). Esto confirma observaciones previas (Aguilar, 2013; Flores \& Telles, 2012; Villarreal, 2010) respecto de la estrecha relación del color de piel con la escolaridad, la ocupación y el ingreso. Las desigualdades en el acceso a la educación, la discriminación en los servicios educativos y el ámbito laboral (véase más adelante), cierto grado de endogamia (Martínez et al., 2014) y las redes sociales que se establecen entre los blancos son algunos de los factores que explican la persistencia del gradiente racista en la posición socioeconómica. Esto evidencia que el privilegio blanco y el racismo están estrechamente relacionados con la estratificación socioeconómica por lo cual difícilmente pueden separarse esas dos formas de inequidad.

Después de ajustar por el HLI y características demográficas y de localidad, se observó que respecto a los blancos, los $\mathrm{MC}$ y $\mathrm{MO}$ (definidos por la percepción de los participantes) tuvieron menor probabilidad de ser profesionistas o patrones. La mayor probabilidad de ser trabajador en el sector informal solo se observó en los MO pero no en los MC. Estos resultados muestran el gradiente racista para ocupar posiciones altas en la estratificación social; pero el ubicarse en baja la posición socioeconómica solo es más probable cuando se tiene la piel más oscura. Pareciera que la "porosidad" de la estratificación es menor conforme se asciende en la escala social. Además, esto no da soporte a la idea de que siempre existe un gradiente racista. 
Tabla 1. Características demográficas y de la localidad de acuerdo al color de piel y el hablar lengua indígena en adultos mexicanos

\begin{tabular}{|c|c|c|c|c|c|c|c|c|c|}
\hline & \multirow[t]{2}{*}{$\begin{array}{c}\text { Población } \\
\text { total }\end{array}$} & \multicolumn{3}{|c|}{$\begin{array}{l}\text { Color de piel: percepción } \\
\text { de participantes }\end{array}$} & \multicolumn{3}{|c|}{$\begin{array}{c}\text { Color de piel: evaluación } \\
\text { del entrevistador }\end{array}$} & \multicolumn{2}{|c|}{$\begin{array}{c}\text { Habla lengua } \\
\text { indígena }\end{array}$} \\
\hline & & $B$ & $M C$ & MO & $B$ & $M C$ & MO & No & Sí \\
\hline & $M$ & $M$ & $M$ & $M$ & $M$ & $M$ & $M$ & $M$ & $M$ \\
\hline \multirow[t]{2}{*}{ Edad } & 38.53 & $0.74^{\mathrm{a}}$ & $7.08^{\mathrm{ac}}$ & $9.54^{\mathrm{C}}$ & 9.19 & 8.19 & 8.60 & 8.35 & 0.76 \\
\hline & $\%$ & $\%$ & $\%$ & $\%$ & $\%$ & $\%$ & $\%$ & $\%$ & $\%$ \\
\hline Mujeres & 52.8 & $4.8^{3}$ & 56.1 & 45.3 & $59.3^{3}$ & 56.4 & 47.3 & 53.0 & 50.2 \\
\hline \multicolumn{10}{|l|}{ Estado civil } \\
\hline Soltero & 27.9 & $7.2^{3}$ & 30.8 & 23.2 & $31.9^{1}$ & 29.0 & 25.6 & $28.7^{2}$ & 18.2 \\
\hline Casado/unión libre & 61.4 & 60.5 & 59.3 & 66.0 & 56.7 & 60.8 & 63.6 & 60.3 & 75.0 \\
\hline Divorciado/separado & 6.0 & 8.2 & 5.4 & 5.5 & 7.2 & 6.2 & 5.4 & 6.3 & 2.7 \\
\hline Viudo & 4.7 & 4.1 & 4.5 & 5.3 & 4.2 & 4.0 & 5.4 & 4.7 & 4.0 \\
\hline \multicolumn{10}{|l|}{ Región } \\
\hline Norte & 21.0 & $27.3^{3}$ & 20.2 & 17.5 & $24.2^{3}$ & 21.4 & 19.4 & $22.5^{2}$ & 1.7 \\
\hline Occidente & 23.6 & 23.8 & 24.2 & 22.4 & 26.0 & 28.1 & 18.7 & 23.7 & 22.1 \\
\hline Centro & 33.6 & 31.5 & 34.4 & 31.7 & 31.7 & 32.5 & 35.2 & 34.1 & 26.5 \\
\hline Sureste & 21.8 & 17.4 & 20.2 & 28.4 & 18.1 & 18.0 & 26.7 & 19.6 & 49.7 \\
\hline \multicolumn{10}{|l|}{ Localidad } \\
\hline Rural & 34.5 & $28.5^{3}$ & 32.0 & 43.5 & $25.3^{3}$ & 32.3 & 39.7 & $30.6^{3}$ & 81.9 \\
\hline Mixto & 13.9 & 11.0 & 13.9 & 16.1 & 11.5 & 13.5 & 15.1 & 14.5 & 6.8 \\
\hline Urbano & 51.6 & 60.5 & 54.1 & 40.4 & 63.2 & 54.2 & 45.2 & 54.9 & 11.3 \\
\hline Habla lengua indígena & 7.6 & $1.8^{3}$ & 5.6 & 15.7 & $2.6^{3}$ & 5.4 & 11.3 & & \\
\hline
\end{tabular}

Abreviaturas: B, blancos; MC, morenos claros; MO, morenos oscuros; M, media. Superíndices diferentes implican diferencias estadísticamente significativas. Diferencias estadísticamente significativas: ${ }^{1} p<0.05,{ }^{2} p<0.010,{ }^{3} p<0.001$.

Fuente: Estimaciones propias a partir de la Enadis (Consejo Nacional para Prevenir la Discriminación, 2010).

Tabla 2. Modelos de regresión lineal o logística en los que las variables dependientes fueron los indicadores de posición socioeconómica y las variables independientes fueron el color de piel y el hablar lengua indígena

\begin{tabular}{|c|c|c|c|c|c|}
\hline & \multicolumn{2}{|c|}{$\begin{array}{c}\text { Color de piel: } \\
\text { percepción de participantes }\end{array}$} & \multicolumn{2}{|c|}{$\begin{array}{c}\text { Color de piel: } \\
\text { evaluación del entrevistador }\end{array}$} & \multirow[t]{2}{*}{$\begin{array}{l}\text { Habla lengua } \\
\text { indígena }\end{array}$} \\
\hline & $M C$ & MO & $M C$ & MO & \\
\hline & $\beta$ & $\beta$ & $\beta$ & $\beta$ & $\beta$ \\
\hline $\begin{array}{l}\text { Escolaridad } \\
\text { (miles de pesos) }^{\mathrm{a}}\end{array}$ & $-0.65^{3}$ & $-1.43^{3}$ & $-0.77^{3}$ & $-1.68^{3}$ & $-1.19^{3}$ \\
\hline Ingreso económico ${ }^{a}$ & $-1.43^{3}$ & $-1.71^{3}$ & $-1.81^{3}$ & $-1.92^{3}$ & $-1.54^{3}$ \\
\hline PSE (bienes en hogar)a & $-0.43^{2}$ & $-1.04^{3}$ & $-0.61^{3}$ & $-0.91^{3}$ & $-1.89^{3}$ \\
\hline Trabajador informal $^{\mathrm{b}}$ & 0.11 & $0.44^{2}$ & 0.04 & 0.22 & 0.53 \\
\hline Trabajador formal ${ }^{b}$ & 0.16 & 0.01 & -0.06 & 0.06 & $-1.02^{0.075}$ \\
\hline Técnico o educación ${ }^{b}$ & 0.29 & 0.08 & 0.37 & -0.01 & 0.35 \\
\hline Profesionista o patrón ${ }^{b}$ & $-0.78^{3}$ & $-1.31^{3}$ & -0.18 & $-0.76^{3}$ & -0.58 \\
\hline
\end{tabular}

Abreviaturas: B, blancos; MC, morenos claro; MO, morenos oscuros; PSE, posición socioeconómica; $\beta$, coeficiente de regresión lineala o logísticab ${ }^{b}$ Grupo de referencia: blancos. Modelos ajustados por sexo, edad, estado civil, tamaño de localidad y región. Los modelos de color de piel están además ajustados por hablar lengua indígena. Los modelos de hablar lengua indígena están ajustados por el color de piel, según la percepción de participantes. Los coeficientes de regresión fueron significativos: ${ }^{1} p<0.05,{ }^{2} p<0.010,{ }^{3} p<0.001$, superíndices indican diferencias marginalmente significativas.

Fuente: Estimaciones propias a partir de la Enadis (Consejo Nacional para Prevenir la Discriminación, 2010).

L. Ortiz Hernández, C. I. Ayala Guzmán, D. Pérez-Salgado | Posición socioeconómica, discriminación y color de piel en México | Perfiles Latinoamericanos, 26(51) | Flacso México | pp. 215-239| DoI: 10.18504/pl2651-009-2018 
Como era de esperarse, las personas que HLI tuvieron menos escolaridad, ingreso y bienes en su hogar. Es bien reconocido que la población indígena históricamente ha sido excluida en términos económicos, lo cual es producto de la desposesión de la que fueron objeto, la falta de inversión estatal y las experiencias de discriminación (Telles \& Flores, 2014). Respecto a la ocupación, en el análisis crudo (tabla A2 del apéndice) las personas que HLI tuvieron menos probabilidad de ser profesionistas o patrones, pero más de ser trabajadores informales. Sin embargo, las diferencias desaparecieron al ajustar por color de piel y otras características demográficas y de la localidad (tabla 2). La única diferencia marginalmente estadística fue en la menor probabilidad de las personas que HLI de tener un empleo formal. Quizá parte de las diferencias en los resultados de la ocupación en cuanto a los otros indicadores de PSE se deba a que las clasificaciones de la ocupación son adecuadas para los contextos urbanos, mientras que las ocupaciones de las áreas rurales están inadecuadamente representadas. También es posible que en las disparidades en ocupación tenga mayor relevancia el color de piel sobre la pertenencia étnica. Es un tema que en el futuro conviene explorar.

\section{Experiencias de discriminación}

En trabajos previos (Aguilar, 2013; Martínez et al., 2014), se había documentado que más personas de piel oscura percibían que habían sufrido discriminación por su acento y color de piel. En congruencia con lo anterior, se observó (con ambas clasificaciones del color de piel) que más MO que blancos pensaban que sus derechos no se habían respetado por su color de piel y que en México existe trato diferencial por ese motivo (tabla 3 y tabla A3 del apéndice). Sin embargo, cuando se analizan las experiencias de discriminación sin implicar su causa (discriminación por acento o color de piel), aparecen otros patrones más complejos.

Un gradiente racista - los MO tuvieron mayor probabilidad que los MC y estos más que los blancos- se observó en diversos eventos de discriminación (tabla 3): no lo quisieron atender en una clínica u hospital y no haber sido aceptado en la escuela. En caso de despido laboral sin justificación y expulsión de la escuela, aunque los dos grupos de morenos tuvieron mayor probabilidad que los blancos de experimentarlas, no se detectó una relación lineal entre color de piel y la discriminación. Interesantemente, más $\mathrm{MC}$, pero no $\mathrm{MO}$, presentaron mayor probabilidad de que no los dejaran entrar a un lugar público y de haber experimentado violencia en el trabajo. En congruencia con lo anterior, investigaciones previas (Castellanos, 2007; Moreno, 2008; Nutini, 
1997; Ortiz, Hernández \& Compean, 2011) habían documentado las variaciones en las experiencias de discriminación en función del color de la piel en México. Un hecho cada vez más reconocido es que los morenos en contextos urbanos pasan por distintas formas de discriminación como la prohibición del acceso a y/o maltrato en lugares públicos (Moreno, 2012; Ortiz, Hernández \& Compean, 2011).

Tabla 3. Modelos de regresión logística con las experiencias de discriminación como variables dependientes y el color de piel y el hablar lengua indígena como variables independientes

\begin{tabular}{|c|c|c|c|c|c|}
\hline & \multicolumn{2}{|c|}{$\begin{array}{l}\text { Color de piel: percepción } \\
\text { de participantes }\end{array}$} & \multicolumn{2}{|c|}{$\begin{array}{c}\text { Color de piel: evaluación } \\
\text { del entrevistadora }\end{array}$} & \multirow[t]{2}{*}{$\begin{array}{l}\text { Habla lengua } \\
\text { Indígena }\end{array}$} \\
\hline & $C$ & 0 & C & 0 & \\
\hline & $\beta$ & $\beta$ & $\beta$ & $\beta$ & $\beta$ \\
\hline Mal trato en trabajo & 0.14 & -0.01 & 0.41 & -0.41 & $-1.78^{1}$ \\
\hline Menor paga por mismo trabajo & -0.63 & -0.73 & -0.63 & -0.79 & 0.75 \\
\hline Despedido sin justificación & $1.86^{2}$ & $1.72^{1}$ & 0.02 & -0.20 & $-1.83^{1}$ \\
\hline Sin atención en clínica u hospital & $0.86^{2}$ & $1.64^{2}$ & $0.83^{1}$ & $1.06^{1}$ & -0.94 \\
\hline $\begin{array}{l}\text { Sin beneficios de programa } \\
\text { social }\end{array}$ & -0.23 & 0.45 & 0.24 & 0.45 & $-1.42^{2}$ \\
\hline No aceptaron en escuela & $2.26^{3}$ & $2.48^{1}$ & -0.25 & 0.48 & 0.44 \\
\hline Lo expulsaron de la escuela & 0.72 & -0.56 & $1.95^{1}$ & $1.89^{1}$ & 0.38 \\
\hline Violencia familiar & $-0.75^{1}$ & 0.29 & -0.47 & 0.03 & $-1.49^{1}$ \\
\hline $\begin{array}{l}\text { No lo dejaron entrar a lugar } \\
\text { público }\end{array}$ & 0.36 & -0.24 & $1.37^{1}$ & 0.90 & $1.85^{1}$ \\
\hline Violencia en la calle & -0.42 & -0.05 & -0.42 & -0.23 & $-1.31^{1}$ \\
\hline Le han dejado de hablar & -0.13 & 0.41 & -0.52 & -0.25 & $-2.49^{1}$ \\
\hline Ha sido humillado en público & -0.94 & -0.76 & $-1.06^{0.082}$ & -1.00 & -0.88 \\
\hline Violencia en la escuela & -0.29 & -0.91 & 0.06 & -0.69 & n.e. \\
\hline Violencia en el trabajo & $2.76^{2}$ & 1.10 & $2.23^{1}$ & 1.80 & -0.62 \\
\hline Ha sido objeto de burlas & $-0.86^{0.061}$ & -0.36 & -0.79 & $-1.04^{0.081}$ & 0.18 \\
\hline Ha sido objeto de rumores & -0.68 & -0.81 & $-1.36^{3}$ & $-1.68^{3}$ & $-1.33^{0.070}$ \\
\hline $\begin{array}{l}\text { Impidieron participar } \\
\text { en actividades }\end{array}$ & 0.37 & 0.76 & -0.51 & 0.84 & -0.79 \\
\hline \multicolumn{6}{|l|}{$\begin{array}{l}\text { Sus derechos no se han } \\
\text { respetado por... }\end{array}$} \\
\hline su apariencia física & -0.00 & 0.27 & -0.09 & 0.19 & -0.48 \\
\hline su color de piel & 0.17 & $0.63^{3}$ & -0.07 & 0.31 & -0.29 \\
\hline no tener dinero & 0.02 & 0.20 & -0.14 & 0.22 & -0.27 \\
\hline sus costumbres & 0.14 & 0.22 & -0.19 & 0.03 & 0.00 \\
\hline su acento al hablar & -0.01 & 0.20 & -0.16 & 0.09 & -0.06 \\
\hline $\begin{array}{l}\text { Existe trato diferencial por color } \\
\text { de piel }\end{array}$ & $0.27^{1}$ & $0.39^{3}$ & $0.33^{2}$ & $0.51^{3}$ & 0.10 \\
\hline
\end{tabular}

Abreviaturas: $\mathrm{B}$, blancos; MC, morenos claros; MO, morenos oscuros; $\beta$, coeficiente de regresión logística; $\mathrm{n}$. e., no estimable. Grupo de referencia: blancos. Modelos ajustados por sexo, edad, estado civil y posición socioeconómica por

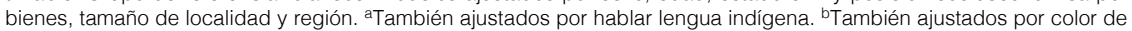
piel según participantes. Los coeficientes fueron significativos: ${ }^{1} p<0.05,{ }^{2} p<0.010,{ }^{3} p<0.001$, otros superíndices indican diferencias marginalmente significativas.

Fuente: Estimaciones propias a partir de la Enadis (Consejo Nacional para Prevenir la Discriminación, 2010).

L. Ortiz Hernández, C. I. Ayala Guzmán, D. Pérez-Salgado | Posición socioeconómica, discriminación y color de piel en México | Perfiles Latinoamericanos, 26(51) | Flacso México | pp. 215-239 | DoI: 10.18504/pl2651-009-2018 
Contrario a lo esperado, en comparación con los MC y/o MO, los blancos tuvieron mayor probabilidad de sufrir violencia familiar, haber recibido burlas, que los humillaran y que inventaran y difundieran rumores acerca de ellos, aunque en algunos casos esas diferencias fueron marginales. En consistencia con esto, en un análisis previo (Aguilar, 2013), se encontró que las personas que se consideraban blancas tuvieron mayor probabilidad de ser víctima de extorsión. Una posible explicación es que los blancos, al tener alta posición socioeconómica, están más sensibilizados con el tema de los derechos humanos, por lo cual identifican más los actos de violencia y discriminación. Es posible además que los blancos sean objeto de agresión por parte de morenos como respuesta de estos últimos a sus experiencias de discriminación.

Otro hallazgo inesperado es que las personas que HLI con menor frecuencia experimentaron maltrato en su trabajo, despido sin justificación, negación de beneficios de programas sociales, violencia familiar, ataques o amenazas, ser objeto de rumores o que les hayan dejado de hablar. Es probable que esto se deba a que la mayoría de la población indígena vive en zonas rurales donde las más de las relaciones se dan fuera de instituciones.

\section{Agrado por el color de piel}

Siguiendo la noción de habitus, podría hipotetizarse que los morenos y la personas que HLI han incorporado y aceptado como válidos los valores dominantes asociados al racismo y al privilegio blanco, los cuales utilizan para evaluarse a sí mismos. Para los dominados el incorporar los valores dominantes implica que se perciban a sí mismos como carentes de un elemento socialmente valorado, lo cual con frecuencia se experimenta como defectos personales (Moreno, 2012; Ortiz, Hernández \& Compean, 2011). De acuerdo con la teoría de la justificación del sistema, los grupos dominados son más afines a las cualidades del exogrupo; mientras que los dominantes tienen actitudes más positivas por el endogrupo (Allport, 1955; Jost, Banaji \& Nosek, 2004). Así, el no contar con ancestro europeo se puede vivir con vergüenza, sentido de inferioridad, de no ser digno y/o como un defecto personal (Harris, 1993). Por el contrario, el privilegio blanco comporta un efecto positivo en las personas que gozan de él (blancos o eurodescendientes), pues les permite crear una identidad positiva.

En congruencia con lo anterior, el agrado por el color de piel en la población total fue mayor en los blancos que en los MO (tabla 4 y tabla A4 del apéndice). Ello verifica un gradiente racista que implica la autodevaluación de las personas de piel oscura, ya que estas han aprendido y aceptado que el color de su piel no es apreciado. Interesantemente entre las mujeres (pero no en los 
hombres) hubo diferencias entre las MC y las blancas. Lo cual puede atribuirse a que entre ellas la acumulación del capital simbólico se da a través de la apariencia física (Bourdieu, 1996).

Tabla 4. Modelos de regresión lineal con el agrado por el color de piel como variable dependiente y el color de piel y el hablar lengua indígena como variables independientes

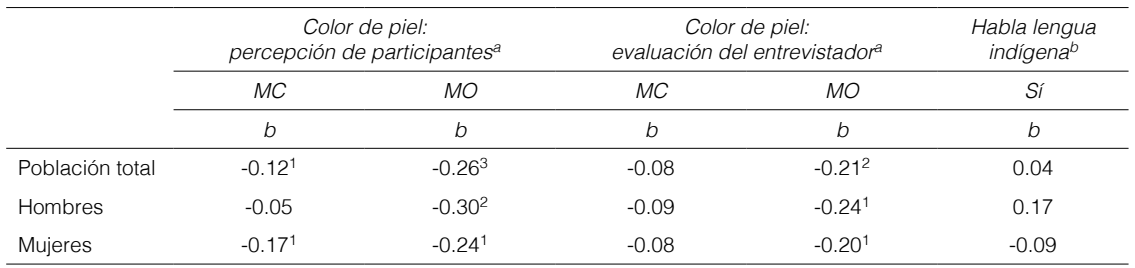

Abreviaturas: MC, morenos claros; MO, morenos oscuros; m, media. Grupo de referencia: blancos. Modelos ajustados por

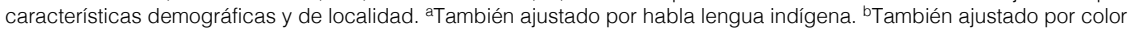
de piel evaluado por entrevistador. Los coeficientes de regresión fueron significativos: ${ }^{1} p<0.05,{ }^{2} p<0.010,{ }^{3} p<0.001$

Fuente: Estimaciones propias a partir de la Enadis (Consejo Nacional para Prevenir la Discriminación, 2010).

La noción de belleza es una construcción social ya que su definición varía entre tiempos y lugares, por lo cual las diferencias en el agrado o desagrado por el color de piel puede ser interpretado como la aceptación de las normas culturales en las cuales la piel blanca es considerada un rasgo positivo. Los mismos grupos dominados aceptan los estereotipos negativos que culturalmente se han construido acerca de ellos y esta situación es una de las explicaciones de la persistencia de las inequidades racistas.

\section{Comentarios finales}

Una fortaleza de este estudio es que se basa en el análisis de una encuesta representativa de los adultos de México, con lo cual los resultados aquí reportados son un panorama de lo que ocurre en la sociedad mexicana. Además, se analizaron dos formas de evaluar el color de piel: las respuestas de los entrevistados y la observación de los entrevistadores. Con ambos métodos se encontró consistencia en los resultados. El uso de paletas de colores o imágenes reduce la posibilidad de que cada persona interprete de manera distinta las preguntas y las opciones de respuesta (Telles \& Flores, 2014). Sin embargo, debe recordarse que aquí el interés no ha sido evaluar un rasgo biológico (la pigmentación de la dermis, por ejemplo), sino conocer el efecto de constructos simbólicos (racialización, racismo y privilegio blanco), para lo cual lo relevante es cómo los sujetos se perciben a sí mismos y son percibidos por las personas con las que interactúan. 
Con el concepto de racismo se buscan las desventajas de la población indígena y la afrodescendiente. En nuestro enfoque teórico, consideramos indispensable incorporar la categoría de privilegio blanco, de acuerdo al cual se espera un gradiente racista en las experiencias de vida. Dos tendencias observadas en el análisis aquí reportado son congruentes con dicho concepto. En primer término, las desigualdades socioeconómicas respecto de la población blanca no se confinan a los indígenas, sino también se observan entre los MC y los MO. En segundo lugar, las disparidades socioeconómicas son mayores en los grupos que están más alejados (simbólicamente) de la población blanca: indígenas y MO. De este modo, el color de piel y la etnicidad se revelan como estrechamente relacionados con la posición socioeconómica: los blancos tienen más acceso a la educación, se ubican en mejores ocupaciones y tienen salarios mayores. Mientras que ciertas formas de discriminación en contextos educativos y laborales son más frecuentes entre los morenos. Conforme la piel es más oscura o el ancestro europeo se "diluye", dicha situación se revierte. Las personas, asimismo, tienen diferentes formas de verse a sí mismas: los blancos se ven en términos más positivos que los morenos. Convendría que futuros estudios sean guiados por ambas categorías, pues son complementarias y permitirán definir hipótesis en cuanto a los efectos de las jerarquías racistas en México.

Al mismo tiempo, otros hallazgos no son acordes con los conceptos de racismo y privilegio blanco. Por ejemplo, no siempre se observa una relación lineal entre el color de piel y la discriminación. Incluso algunas experiencias de este tipo y la violencia son más comunes entre los blancos. De cualquier modo, todo esto indica que en la sociedad mexicana la racialización es una realidad en tanto que las experiencias de las personas presentan una distribución asociada al color de piel. Además, la racialización genera conflictos en las relaciones interpersonales.

Hay que subrayar que las diferencias de acuerdo al color de piel en las experiencias de discriminación surgen después de ajustar por posición socioeconómica. Así, aunque esta última se relaciona de cerca con el color de la piel, al mismo tiempo tiene un efecto independiente sobre experiencias vitales a las que se enfrentan las personas. Entonces es necesario reconocer que aunque el racismo y el privilegio blanco son fenómenos vinculados a otras formas de desigualdad social, al mismo tiempo gozan de una dinámica propia.

Estudios hechos a partir del concepto de etnicidad han documentado las disparidades socioeconómicas y de bienestar que sufre la población indígena (Saldívar, 2012). Las experiencias de discriminación que ellos enfrentan en las ciudades son otra expresión del racismo asociado a la pertenencia étnica (Castellanos, 2003, 2007). En respuesta a esas inequidades los gobiernos locales y federales han creado políticas y programas para promover los derechos de la población indígena. La protección de los derechos de los pueblos indígenas es incluso una garantía 
protegida constitucionalmente. Los hallazgos aquí expuestos reafirman las observaciones de otras investigaciones respecto de las inequidades socioeconómicas - pero no en experiencias de discriminación en contextos específicos- asociadas a la pertenencia a un grupo indígena; ello implica que se debe continuar con los programas de protección orientados a las "minorías étnicas".

$\mathrm{Al}$ mismo tiempo, nuestro modelo teórico y los resultados evidencian que dicho abordaje, aunque necesario, es insuficiente para dar cuenta de todas las manifestaciones del privilegio blanco y el racismo. De esta forma, las diferencias por color de piel en posición socioeconómica y discriminación aquí reportadas no podrían indagarse ni explicarse por el concepto de etnicidad. Más aún, las diferencias en ocupación de acuerdo a la pertenencia de un grupo indígena dejaron de existir al incluir el color de piel. Es decir, la capacidad de explicación del color de piel, como un marcador del capital cultural asociado con la ascendencia europea, es mayor que la pertenencia étnica. Así, mientras que menos del $4 \%$ de la población puede ser considerada indígena, más del $70 \%$ de las personas en México son morenas. El concepto de etnicidad solo se concentra en las desventajas de la población indígena "minoritaria" enfatizando en que los problemas a los que se enfrentan derivan de sus diferencias sociolingüísticas en relación con la mayoría mestiza. En contraste, con las nociones de racismo y privilegio blanco se llama la atención sobre las ventajas que goza una minoría (blanca) en detrimento de la "mayoría" (de morenos) de la población mexicana. En este sentido, el enfoque aquí desarrollado implica que las inequidades racistas se originan en el poder asociado a constructos socioculturales - como los prejuicios asociados al ser indígena y los estereotipos positivos asociados a lo europeo- que permean a la sociedad en su conjunto.

En el futuro se requieren diseñar y concretar investigaciones que documenten de manera más detallada y específica la existencia y los efectos de la racialización, el racismo y el privilegio blanco. Luego de los resultados de esta investigación quedan varios interrogantes: ¿existe una forma "ideal" de evaluar los fenotipos simbólicamente asociados a ciertos ancestros geográficos o son complementarias?, ¿̨cómo se da la interacción entre afrodescendientes, indígenas, morenos y blancos en términos de mantenimiento y reproducción del capital simbólico asociado al privilegio blanco?, ¿por qué las personas blancas sufren y/o reportan con mayor frecuencia ciertas formas de violencia?, ¿qué diferencias entre hombres y mujeres y entre grupos de edad se observan respecto de la vivencia del racismo y el privilegio blanco?, ¿cómo se socializan el privilegio blanco y el racismo entre los niños?, ¿qué papel cumplen los medios masivos de comunicación en la reproducción del racismo y el privilegio blanco?. Queda pendiente determinar la forma más conveniente de evaluar las experiencias de discriminación. Ha sido común examinarlas con base en el color de piel y el 
acento al hablar (Aguilar, 2013; Martínez et al., 2014). Estas maneras de medir el prejuicio pueden estar sesgadas dado que es posible que las personas atribuyan ciertos eventos al cómo perciben a los otros con los que interactúan. Más aún, es difícil que las personas tengan certeza de la causa de los eventos de discriminación (i. e., que el evento discriminatorio sea realmente por el color de piel). Por ello conviene más preguntar sobre la discriminación sin implicar sus causas, tal como se realizó en una muestra por conveniencia de estudiantes universitarios (Ortiz, Hernández \& Compean, 2011).

Es importante eliminar el racismo y el privilegio blanco pues afectan negativamente en diferentes esferas de la vida a la mayoría de la población mexicana no blanca. La progresiva reducción del racismo y del privilegio blanco debe incorporarse a la agenda de la política y la política pública. Se requiere que las instituciones y políticas que combaten la discriminación amplíen su atención, agregando la discriminación por etnia (indígenas o afrodescendientes) y a otras expresiones del racismo como las desventajas de los morenos. Continuar con la documentación y denuncia de las disparidades racistas sería el primer paso para construir una sociedad igualitaria. Aunque sigue sin definir cuál es la mejor forma de evaluar los fenotipos simbólicamente asociados a los ancestros geográficos, es urgente que de manera sistemática se indague el color de piel (u otros rasgos físicos vinculados al ancestro) en las estadísticas oficiales (censo y encuestas). De este modo se contaría con información para saber sobre la evolución de las desigualdades racistas.

Guiado por el concepto de racismo, en este trabajo se ha documentado que los morenos son discriminados con más frecuencia en servicios públicos y privados — como los de salud y los educativos—, así como en el ámbito laboral. Estos son áreas de oportunidad para incidir en el corto plazo ya que se pueden diseñar políticas y programas que desaliente la discriminación interpersonal en contextos institucionales. Es posible diseñar e implementar programas de sensibilización dirigidos a servidores públicos y trabajadores de servicios privados en relación con las formas y el impacto de la discriminación interpersonal.

No obstante, dichos programas no aseguran que se elimine el privilegio blanco. Es decir, evitar las prácticas discriminatorias hacia morenos e indígenas no necesariamente reducirá el trato preferencial hacia los blancos. Para ello se requieren establecer políticas en instituciones públicas y privadas que garanticen que las personas son evaluadas de acuerdo a sus capacidades y méritos, y no por el capital simbólico derivado de sus rasgos físicos y/o sus vínculos sociales. En los medios masivos de comunicación predomina la presentación de personas blancas asociadas a la riqueza y el éxito. Una medida podría ser que en dichos medios se promoviera la diversidad en términos de color de piel y etnicidad. Se requieren medidas de acción afirmativa en las que se reconozca que las personas que no son blancas llevan sobre sí una desventaja históricamente construida. Revertir 
el racismo y el privilegio blanco será una tarea difícil y de largo plazo pues se encuentran enraizados en la sociedad y en la mente de los mexicanos desde hace siglos, de modo que ahora son vistos como un hecho "natural" y/o inmutable.

\section{Referencias}

Aguilar, R. (2013). Los tonos de los desafíos democráticos. El color de la piel y la raza en México. Política y Gobierno, (Volumen temático), 25-55.

Allport, G. (1955). La naturaleza del prejuicio. Buenos Aires: Editorial Universitaria de Buenos Aires.

Pierre, B. (1996). La dominación masculina. Revista de Estudios de Género, La Ventana, 23(3), $322-325$.

Castellanos, A. (2007). El discurso racista en México. En Van Dijk, T. A. Racismo y discurso en América Latina (pp. 285-332). Barcelona: Gedisa.

Castellanos, A. (2003). Imágenes racistas en ciudades del sureste. En Castellanos, A. Imágenes del racismo en México (pp. 35-143). México: Universidad Autónoma Metropolitana/Plaza y Valdés.

Clark, R., Anderson, N., Clark, V. \& Williams, D. (1999). Racism as a Stressor for African Americans. American Psychologist, 54(10), 805-816.

Consejo Nacional para Prevenir la Discriminación (2010). Encuesta Nacional sobre Discriminación en México, México: Conapred. Recuperado el 15 de junio de 2011, de http://www.conapred .org.mx.

Flores, R. \& Telles, E. (2012). Social Stratification in Mexico: Disentangling Color, Ethnicity, and Class. American Sociological Review, 77(3), 486-494.

Gall, O. (2004). Identidad, exclusión y racismo: reflexiones teóricas y sobre México. Revista Mexicana de Sociologia, 66(2), 221-259.

Harris, C. (1993). Whiteness as Property. Harvard Law Review, 106(8), 1707-1791.

Hooker, J. (2005). Indigenous Inclusion/Black Exclusion: Race, Ethnicity and Multicultural Citizenship in Latin America. Journal of Latin American Studies, (37), 285-310.

Jost, J., Banaji, M. \& Nosek, B. (2004). A Decade of System Justification Theory: Accumulated Evidence of Conscious and Unconscious Bolstering of the Status Quo, Political Psychology, 25(6), 881-919. 
Knight, A. (1990). Racism, Revolution and Indigenismo: Mexico, 1910-1940. En Graham, R. (Eds.). The Idea of Race in Latin America, 1870-1940 (pp. 71-114). Austin: University of Texas Press.

Lida, C. (1994). Prólogo. En Lida, C. Una inmigración privilegiada. Comerciantes, empresarios y profesionales españoles en México en los siglos XIX y XX (pp. 13-24). México: Alianza Editorial.

Lida, C. (1985). Inmigrantes españoles durante el porfiriato: problemas y temas. Historia Mexicana, 35(2), 219-239.

Martínez, R. Saldívar, E., Flores, R. \& Sue, C. (2014). The Different Faces of Mestizaje. Ethnicity and Race in Mexico. En Telles, E. (Ed.). Pigmentocracies. Ethnicity, Race, and Color in Latin America (pp. 36-80). North Carolina: University of North California Press.

McCaa, R., Schwartz, S., Grubessich, A. (1979). Race and Class in Colonial Latin America Critique. Comparative Studies in Society and History, (21), 421-433.

Moreno, M. (2012). Yo nunca he tenido la necesidad de nombrarme: reconociendo el racismo y el mestizaje en México. En Castellanos, A. \& Landázuri, G. Racismos y otras formas de intolerancia de Norte a Sur en América Latina (pp. 15-48). México: Juan Pablos Editor.

Moreno, M. (2008). Historically-Rooted Transnationalism: Slightedness and the Experience of Racism in Mexican Families. Journal of Intercultural Studies, 29, 283-297.

Morner, M. (1966). History of Race Relations in Latin-America. Latin American Research Review, 1(3), 17-44.

Morner, M. (1962). El mestizaje en la historia de Ibero-América. Informe preliminar. Revista de Historia de América, (53/54), 128-169.

Nutini, H. (1997). Class and Ethnicity in Mexico: Somatic and Racial Considerations. Ethnology, 36(3), 227-38.

Ortiz-Hernández, L., Compean-Dardón, S., Verde-Flota, E. \& Flores-Martínez, M. N. (2011). Racism and Mental Health Among University Students in Mexico City. Salud Pública de México, 53(2), 125-133.

Quillian, L. (2006). New Approaches to Understanding Racial Prejudice and Discrimination. Annual Review of Sociology, 32, 299-328.

Saldívar, E. (2012). Racismo en México: apuntes críticos sobre etnicidad y diferencias culturales. En Castellanos, A. Racismos y otras formas de intolerancia de Norte a Sur en América Latina (pp. 49-76). México: Juan Pablos Editor. 
Stephens, T. (1989). Dictionary of Latin American Racial and Ethnic Terminology, Gainesville, Fl: University Press of Florida.

Telles, E. \& Flores, R. (2014). A Comparative Analysis of Ethnicity, Race, and Color in Latin America Based on perla Findings. En Telles, E. (Ed.). Pigmentocracies (pp. 218-236). North Carolina: University of North California Press.

Villarreal, A. (2010). Stratification by Skin Color in Contemporary Mexico. American Sociological Review, 75(5), 652-678.

Wade, P. (2010). Race and Ethnicity in Latin America. Londres: Pluto Press.

\section{Apéndice}

Tabla A1. Análisis factorial de los bienes en el hogar. Enadis 2010

\begin{tabular}{|c|c|c|}
\hline & $\begin{array}{l}\text { Hogares que cuentan con los bienes } \\
\text { (\%) }\end{array}$ & Factor 1 \\
\hline Eigen value & & 4.56 \\
\hline$\%$ de la varianza & & 77.8 \\
\hline \multicolumn{3}{|l|}{ Bienes } \\
\hline Radio o radio grabadora & 82.75 & 0.27 \\
\hline Televisión & 97.39 & 0.24 \\
\hline Video casetera & 53.00 & 0.42 \\
\hline Licuadora & 90.98 & 0.38 \\
\hline Lavadora & 77.55 & 0.53 \\
\hline Refrigerador & 89.74 & 0.42 \\
\hline Teléfono fijo (de casa) & 50.63 & 0.58 \\
\hline Teléfono móvil (celular) & 64.47 & 0.42 \\
\hline Automóvil o camioneta propios & 42.54 & 0.53 \\
\hline Computadora & 31.82 & 0.54 \\
\hline Lavadero & 86.36 & 0.26 \\
\hline Fregadero o tarja & 64.89 & 0.60 \\
\hline Lavabo & 68.51 & 0.68 \\
\hline Regadera & 71.18 & 0.64 \\
\hline Cisterna o aljibe & 29.27 & 0.38 \\
\hline Tinaco en la azotea & 50.99 & 0.43 \\
\hline Pileta, tanque o depósito de agua & 35.96 & 0.06 \\
\hline Calentador de gas & 46.05 & 0.60 \\
\hline Calentador de otro combustible & 7.17 & 0.07 \\
\hline Bomba de agua & 20.97 & 0.43 \\
\hline Tanque de gas estacionario & 16.98 & 0.31 \\
\hline Aire acondicionado & 12.65 & 0.30 \\
\hline Calefacción & 4.47 & 0.23 \\
\hline
\end{tabular}


Tabla A2. Indicadores de posición socioeconómica de acuerdo al color de piel y hablar lengua indígena en adultos mexicanos. Enadis 2010

\begin{tabular}{|c|c|c|c|c|c|c|c|c|c|}
\hline & \multirow[t]{2}{*}{$\begin{array}{c}\text { Población } \\
\text { total }\end{array}$} & \multicolumn{3}{|c|}{$\begin{array}{l}\text { Color de piel: } \\
\text { percepción de } \\
\text { participantes }\end{array}$} & \multicolumn{3}{|c|}{$\begin{array}{l}\text { Color de piel: } \\
\text { evaluación } \\
\text { del entrevistador }\end{array}$} & \multicolumn{2}{|c|}{$\begin{array}{c}\text { Habla alguna } \\
\text { indígena }\end{array}$} \\
\hline & & $B$ & $M C$ & MO & $B$ & $M C$ & MO & No & Sí \\
\hline & M & M & $M$ & M & M & M & M & M & M \\
\hline Escolaridad (años) & 9.09 & $9.77^{\mathrm{b}}$ & $9.36^{\mathrm{c}}$ & $7.97^{\mathrm{bc}}$ & $10.30^{\mathrm{ab}}$ & $9.41^{\mathrm{ac}}$ & $8.32^{\mathrm{bc}}$ & $9.28^{a}$ & $6.40^{\mathrm{a}}$ \\
\hline Ingreso (miles de pesos) & 7.51 & $9.00^{\mathrm{ab}}$ & $7.47^{\mathrm{a}}$ & $6.49^{b}$ & $9.63^{\mathrm{ab}}$ & $7.40^{\mathrm{a}}$ & $6.88^{b}$ & $7.79^{\mathrm{a}}$ & $3.84^{\mathrm{a}}$ \\
\hline PSE (bienes en el hogar) & 7.17 & $8.05^{b}$ & $7.42^{\mathrm{c}}$ & $6.16^{\mathrm{bc}}$ & $8.31^{\mathrm{ab}}$ & $7.37^{\mathrm{a}}$ & $6.66^{b}$ & $7.50^{\mathrm{a}}$ & $3.61^{a}$ \\
\hline Ocupación & $\%$ & $\%$ & $\%$ & $\%$ & $\%$ & $\%$ & $\%$ & $\%$ & $\%$ \\
\hline Trabajador informal & 63.1 & $55.2^{\star * \star}$ & 61.6 & 71.2 & $57.0^{\star \star \star}$ & 61.3 & 66.7 & $61.1^{* \star *}$ & 84.5 \\
\hline Trabajador formal & 24.0 & 25.4 & 25.6 & 20.5 & 26.3 & 23.3 & 23.9 & 25.6 & 7.1 \\
\hline Técnico o educación & 4.9 & 4.1 & 5.5 & 4.4 & 4.2 & 6.0 & 4.1 & 4.7 & 6.6 \\
\hline Profesionista o patrón & 8.0 & 15.3 & 7.3 & 3.9 & 12.5 & 9.4 & 5.3 & 8.6 & 1.8 \\
\hline
\end{tabular}

Abreviaturas: M, media; B, blancos; MC, morenos claros; MO, morenos oscuros; PSE, posición socioeconómica. Diferencias estadísticamente significativas: ${ }^{\star} p<0.05,{ }^{* \star} p<0.010$, ${ }^{\star \star \star} p<0.001$. Superíndices iguales implican diferencias estadísticamente significativas.

Fuente: Estimaciones propias con base en la Enadis (Consejo Nacional para Prevenir la Discriminación, 2010).

Tabla A3. Experiencias de discriminación de acuerdo al color de piel y el hablar lengua indígena en adultos mexicanos. Enadis 2010

\begin{tabular}{|c|c|c|c|c|c|c|c|c|c|}
\hline & \multirow{2}{*}{$\begin{array}{c}\text { Población } \\
\text { total }\end{array}$} & \multicolumn{3}{|c|}{$\begin{array}{c}\text { Color de piel: percepción de } \\
\text { participantes }\end{array}$} & \multicolumn{3}{|c|}{$\begin{array}{c}\text { Color de piel: evaluación del } \\
\text { entrevistador }\end{array}$} & \multicolumn{2}{|c|}{$\begin{array}{l}\text { Habla lengua } \\
\text { indígena }\end{array}$} \\
\hline & & $B$ & $M C$ & MO & $B$ & $M C$ & MO & No & Sí \\
\hline & $\%$ & $\%$ & $\%$ & $\%$ & $\%$ & $\%$ & $\%$ & $\%$ & $\%$ \\
\hline Mal trato en trabajo & 4.3 & 4.5 & 4.5 & 3.9 & 5.0 & 5.8 & 2.7 & $4.6^{* *}$ & 0.8 \\
\hline $\begin{array}{l}\text { Menor paga por } \\
\text { mismo trabajo }\end{array}$ & 3.0 & 4.8 & 2.5 & 2.4 & 5.8 & 2.4 & 2.4 & 3.0 & 3.5 \\
\hline $\begin{array}{l}\text { Despedido sin } \\
\text { justificación }\end{array}$ & 1.1 & $0.2^{*}$ & 1.5 & 1.2 & 1.2 & 1.2 & 1.0 & $1.2^{* \star \star}$ & 0.2 \\
\hline $\begin{array}{l}\text { Sin atención en } \\
\text { clínica u hospital }\end{array}$ & 3.7 & $1.2^{* *}$ & 3.3 & 6.9 & 1.4 & 3.6 & 4.8 & 3.8 & 3.3 \\
\hline $\begin{array}{l}\text { Sin beneficios de } \\
\text { programa social }\end{array}$ & 4.5 & 4.4 & 3.6 & 6.4 & 3.5 & 4.3 & 5.2 & $4.7^{*}$ & 1.8 \\
\hline $\begin{array}{l}\text { No aceptaron en } \\
\text { escuela }\end{array}$ & 1.0 & 0.1 & 1.4 & 1.1 & 1.0 & 0.7 & 1.3 & 1.0 & 0.6 \\
\hline $\begin{array}{l}\text { Lo corrieron de } \\
\text { la escuela }\end{array}$ & 0.3 & 0.2 & 0.4 & 0.1 & 0.0 & 0.4 & 0.3 & 0.3 & 0.1 \\
\hline Violencia familiar & 4.1 & 5.4 & 2.4 & 6.1 & 5.6 & 2.8 & 4.6 & $4.3^{*}$ & 0.9 \\
\hline $\begin{array}{l}\text { No lo dejaron entrar } \\
\text { a lugar público }\end{array}$ & 1.6 & 1.3 & 2.1 & 0.9 & 0.6 & 2.3 & 1.4 & 1.5 & 2.3 \\
\hline Violencia en la calle & 6.5 & 8.5 & 5.6 & 6.4 & 9.4 & 5.4 & 6.2 & $6.9^{* * *}$ & 1.1 \\
\hline $\begin{array}{l}\text { Le han dejado de } \\
\text { hablar }\end{array}$ & 3.6 & 3.4 & 3.1 & 4.7 & 4.9 & 2.8 & 3.7 & $3.8^{* *}$ & 0.4 \\
\hline $\begin{array}{l}\text { Ha sido humillado } \\
\text { en público }\end{array}$ & 2.4 & 4.7 & 1.5 & 1.8 & 5.70 .083 & 1.5 & 1.7 & 2.5 & 0.7 \\
\hline $\begin{array}{l}\text { Violencia en la } \\
\text { escuela }\end{array}$ & 0.9 & 1.1 & 1.1 & 0.5 & 1.0 & 1.3 & 0.6 & 1.0 & 0.0 \\
\hline Violencia en el trabajo & 0.7 & $0.1^{\star \star \star}$ & 1.3 & 0.2 & 0.2 & 1.1 & 0.6 & 0.8 & 0.2 \\
\hline
\end{tabular}


Tabla A3. Continuación

\begin{tabular}{|c|c|c|c|c|c|c|c|c|c|}
\hline & \multirow{2}{*}{$\begin{array}{c}\text { Población } \\
\text { total }\end{array}$} & \multicolumn{3}{|c|}{$\begin{array}{c}\text { Color de piel: percepción de } \\
\text { participantes }\end{array}$} & \multicolumn{3}{|c|}{$\begin{array}{c}\text { Color de piel: evaluación del } \\
\text { entrevistador }\end{array}$} & \multicolumn{2}{|c|}{$\begin{array}{c}\text { Habla lengua } \\
\text { indígena }\end{array}$} \\
\hline & & $B$ & $M C$ & MO & $B$ & $M C$ & $M O$ & No & Sí \\
\hline & $\%$ & $\%$ & $\%$ & $\%$ & $\%$ & $\%$ & $\%$ & $\%$ & $\%$ \\
\hline $\begin{array}{l}\text { Ha sido objeto } \\
\text { de burlas }\end{array}$ & 4.7 & 7.7 & 3.2 & 5.0 & 9.9 & 4.0 & 3.3 & 4.9 & 3.3 \\
\hline $\begin{array}{l}\text { Ha sido objeto } \\
\text { de rumores }\end{array}$ & 4.3 & 6.8 & 3.8 & 3.0 & $11.5^{\star \star \star}$ & 3.1 & 2.3 & $5.6^{\star}$ & 1.0 \\
\hline $\begin{array}{l}\text { Impidieron participar } \\
\text { en actividades }\end{array}$ & 0.5 & 0.5 & 0.5 & 0.7 & 0.50 .083 & 0.2 & 0.9 & 0.6 & 0.1 \\
\hline \multicolumn{10}{|l|}{$\begin{array}{l}\text { Sus derechos no se } \\
\text { han respetado por ... }\end{array}$} \\
\hline su apariencia física & 24.0 & $22.4^{\star \star}$ & 22.4 & 28.1 & $22.4^{\star \star}$ & 21.1 & 27.1 & 24.2 & 21.7 \\
\hline su color de piel & 17.5 & $13.0^{\star \star \star}$ & 15.7 & 24.3 & $14.6^{\star \star \star}$ & 14.3 & 21.5 & 17.1 & 22.1 \\
\hline no tener dinero & 32.5 & $30.0^{*}$ & 31.6 & 36.2 & $30.4^{\star \star *}$ & 28.2 & 37.1 & 32.4 & 33.5 \\
\hline sus costumbres & 16.8 & $14.0^{*}$ & 16.4 & 19.6 & $16.1^{*}$ & 14.4 & 19.1 & $16.2^{*}$ & 24.0 \\
\hline su acento al hablar & 17.1 & $15.2^{\star \star}$ & 15.7 & 21.2 & $15.6^{\star \star}$ & 14.5 & 19.9 & $16.5^{\star}$ & 25.0 \\
\hline $\begin{array}{l}\text { En México existe trato } \\
\text { diferencial por color } \\
\text { de piel }\end{array}$ & 58.0 & $35.6^{\star \star}$ & 43.1 & 44.4 & $33.8^{\star \star \star}$ & 41.0 & 45.6 & 41.8 & 43.2 \\
\hline
\end{tabular}

Abreviaturas: B, blancos; MC, morenos claros; $\mathrm{MO}$, morenos oscuros. Los coeficientes de regresión fueron significativos: ${ }^{*} p<0.05,{ }^{* *} p<0.010,{ }^{* *} p<0.001$. Superíndices indican diferencias marginalmente significativas.

Fuente: Estimaciones propias con base en la Enadis 2010 (Consejo Nacional para Prevenir la Discriminación, 2010).

Tabla A4. Agrado por color de piel ${ }^{1}$ de acuerdo al color de piel y el hablar lengua indígena en adultos mexicanos. Enadis 2010

\begin{tabular}{lc|ccc|ccc|cc}
\hline & & \multicolumn{3}{|c|}{$\begin{array}{c}\text { Color de piel: } \\
\text { percepción participantes }\end{array}$} & \multicolumn{3}{c|}{$\begin{array}{c}\text { Color de piel: } \\
\text { evaluación entrevistador }\end{array}$} & \multicolumn{2}{c}{$\begin{array}{c}\text { Habla lengua } \\
\text { indígena }\end{array}$} \\
\cline { 2 - 10 } & & $B$ & $M C$ & MO & B & MC & MO & No & Si \\
\cline { 2 - 10 } & $m$ & $m$ & $m$ & $m$ & $m$ & $m$ & $m$ & $m$ & $M$ \\
\hline Población total & 9.40 & $9.47 \mathrm{~b}$ & 9.35 & $9.23 \mathrm{~b}$ & $9.47 \mathrm{~b}$ & 9.39 & $9.25 \mathrm{~b}$ & 9.34 & 9.35 \\
Hombres & 9.41 & 9.47 & 9.42 & 9.20 & 9.51 & 9.42 & 9.27 & 9.34 & 9.50 \\
Mujeres & 9.40 & 9.48 & 9.30 & 9.26 & 9.44 & 9.36 & 9.24 & 9.34 & 9.20 \\
\hline
\end{tabular}

Abreviaturas: B, blancos; MC, morenos claro; MO, morenos oscuros; $\mathrm{m}$, medias ponderadas; ${ }^{1}$ Escala de 0 (nada de agrado) a 10 (le gusta mucho). Superíndices iguales implican diferencias estadísticamente significativas.

Fuente: Estimaciones propias con base en la Enadis 2010 (Consejo Nacional para Prevenir la Discriminación, 2010).

Recibido el 25 de septiembre de 2015.
Aceptado el 17 de enero de 2017.

L. Ortiz Hernández, C. I. Ayala Guzmán, D. Pérez-Salgado | Posición socioeconómica, discriminación y color de piel en México | Perfiles Latinoamericanos, 26(51) | Flacso México | pp. 215-239 | DoI: 10.18504/pl2651-009-2018 